\title{
Efficacy of N-phenylphtalamic acid in some Solanaceae species
}

\author{
Chauhan, S. V. S., Singh, R. R. and Gupta, H. K. \\ Department of Botany School of life Sciences Dr. B.R. Ambedkar University, Agra, India
}

Summary: N-phenylphthalamic acid-C14H11 NO3 (Nevirol $60 \mathrm{WP}$ ) was successfully used for enhancing yield in some important vegetable crops namely, tomato (Lycopersicon esculentum), chilli (Capsicum annuum) and brinjal (Solanum melongena) of Solanaceae. Aqueous sprays with $0.2 \%$ and $3.0 \%$ significantly enhanced fruit production in chilli and tomato respectively. On the other hand, various treatments in brinjal failed to enhance yield significantly. The increase in yield in both tomato and chilli is largely due to increase in the number of flowers and fruit-set percentage.

Key words: Nevirol, Lycopersicon esculentum, Capsicum annuum, Solanum malongena

\section{Introduction}

Growers always aim for an increase in the yield of their crops which can be enhanced up to 5 to $30 \%$ through better fruit setting, disadvantageous influence of the growing circumstances, such as agrotechnical failures, bad weather conditions, absences of optimal varieties may be greatly eliminated. Through these effects, fluctuations in yield can be eliminated and yield can be promoted.

Nevirol 60 WP is a compound used as a fruit setter and represents a new and significant development for the increase of crop production. It is widely used in almost all kinds of crops such as field, vegetable, fruits crops, and flowers. It reduces the undesirable effects caused by conditions beyond control (weather, failures in agrotechniques, etc) and thus compensate the yield fluctuation (Anonymous, 2000).

Chemically nevirol is $\mathrm{N}$-phenylphtalamic acid $\left(\mathrm{C}_{14} \mathrm{H}_{11} \mathrm{O}_{3}\right)$. The chemical structure is:

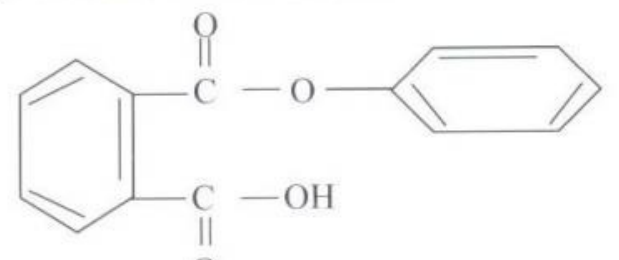

$\mathrm{O}$

The Nevirol is practically non-toxic, and it may be mixed with insecticides, fungicides and folios fertilizers except alkaline product. Application of the Nevirol is recommended at full bloom stage of the vegetable and fruit crops (Racskó et al., 2005; Thurzó et al, 2005). It can also be used in a greenhouse cultivation, foil home as well as in field cultivation for various crops e.g. pea, beans, soya, alfalfa, rape and rice.

Present investigation was undertaken to test the efficiency of nevirol in three important vegetable crops of the family Solanaceae, namely, tomato, chilli and brinjal.

\section{Material and method}

The seeds of tomato (Lycopersicon esculentum L. Var. Choice - 21), chilli (Capsicum annuum L. Var. Pusa-Jwala) and brinjal (Solanum melongena L. Var. Pusa-Kranti) were obtained from National Seed Corporation, Agra and were sown at Botanical Garden, School of Life Sciences, Dr. B. R. Ambedkar University, Agra. The seedlings after 25 days of sowing at 4-5 leaf stage were transplanted in the fields. The experiment was laid out in randomized row design with ten replicates of each variety. The distance between row to row was $75 \mathrm{~cm}$ and plant to plant was $50 \mathrm{~cm}$. The plants of all the three species were sprayed with 1.0, 2.0 and $3.0 \%$ nevirol at different developmental stages. A group of 40 plants were sprayed three days after with nevirol at floral bud initiation $\left(\mathrm{T}_{1}\right)$. A group of 20 plants receiving first treatments $\left(\mathrm{T}_{1}\right)$ were sprayed again at the time of full blooming $\left(\mathrm{T}_{2}\right)$. Individual plants were sprayed with $10 \mathrm{ml}$ of concerned solution to run off. A group of 20 plants were grown between the rows of treated plants and were sprayed with distilled water to serve as control $\left(\mathrm{T}_{0}\right)$.

Data of plant height, number of branches/plant, number of flowers/plant, number of fruits/plant, fruit-set percentage/plant and total yield/plant were obtained from treated and control plants and statistically analyzed.

\section{Result}

Plant height

All the treatments with various concentrations of nevirol suppressed plant height in all the three crops (Table 1). The maximum reduction $(65.0 \mathrm{~cm})$ was observed in tomato plants treated twice with $3.0 \%$ as compared to $85.3 \mathrm{~cm}$ plant height/ control plant. On the other hand, in chilli and brinjal, the 
plant height decreased by two sprays of $2.0 \%$ solution. The maximum reduction was recorded in chilli $(22.0 \mathrm{~cm})$ and brinjal $(42.5 \mathrm{~cm})$ such treatments as compared to their control plants 57.0 and $48.1 \mathrm{~cm}$ respectively.

\section{Number of branches / plant}

It is clear from Table 1 that the number of branches/plant were enhanced in tomato and chilli plants by the treatments with $1 \%$ and $2 \%$ concentrations. However, the number of branches/plant increased by the treatment of $3.0 \%$ as compared to the lower concentration.

On the other hand, in brinjal the number of branches/plant decreased with the increase in the concentrations as well as number of treatments. There was minimum reduction in tomato (82.0), Chilli (26.0) and brinjal (11.0) as compared to tomato (56.0), Chilli (17.0) and brinjal (14.2)/control plants.

\section{Days taken to first flowering}

All the treatments with various concentrations of Nevirol reduced the number of days taken to first flower appearances in all three crops (Table 1). In tomato, the first flower opened 5 days before as compared to 57.0 days taken by the plants treated twice with $2.0 \%$. On the other hand, the first flower appeared after 56.5days in chilli and 104.0 days in brinjal plants receiving single treatment of $3.0 \%$ as compared to 58.0 and 108.7 days by control plants respectively.

\section{Number of flowers/plant}

The number of flowers/plant increased in all these three crops by treatments with various concentrations (Table l). Minimum reduction in the number of flowers/plant was recorded in tomato plants sprayed twice with $3.0 \%$ concentration. On the other hand, in chilli and brinjal plants minimum reduction (78.4 and 38.2) was recorded when treated twice with $2.0 \%$ as compared to 67.5 and 32.0 flowers/control plants respectively.

\section{Number of fruits/plant}

There was a significant increase in the number of fruits/plant in all the three crop treated with nevirol. The number of fruits/plant gradually increased in those plant. The maximum number of fruits/plant were recorded in tomato plants (153.0) treated twice with $2.0 \%$ as compared to their 93.8 fruits/ control plant. Increase in the number of fruits/plant has also been recorded in chilli and brinjal plants treated twice with $3.0 \%$ Nevirol.

It is clear from Table 1 that number of fruit/plant was significantly enhanced with the increase in the concentration as well as treatments. This increase was directly proportional

Table 1 Effect of nevirol on various parameters in Lycopersicon esculentum Capsicum annum and Solanum melongena

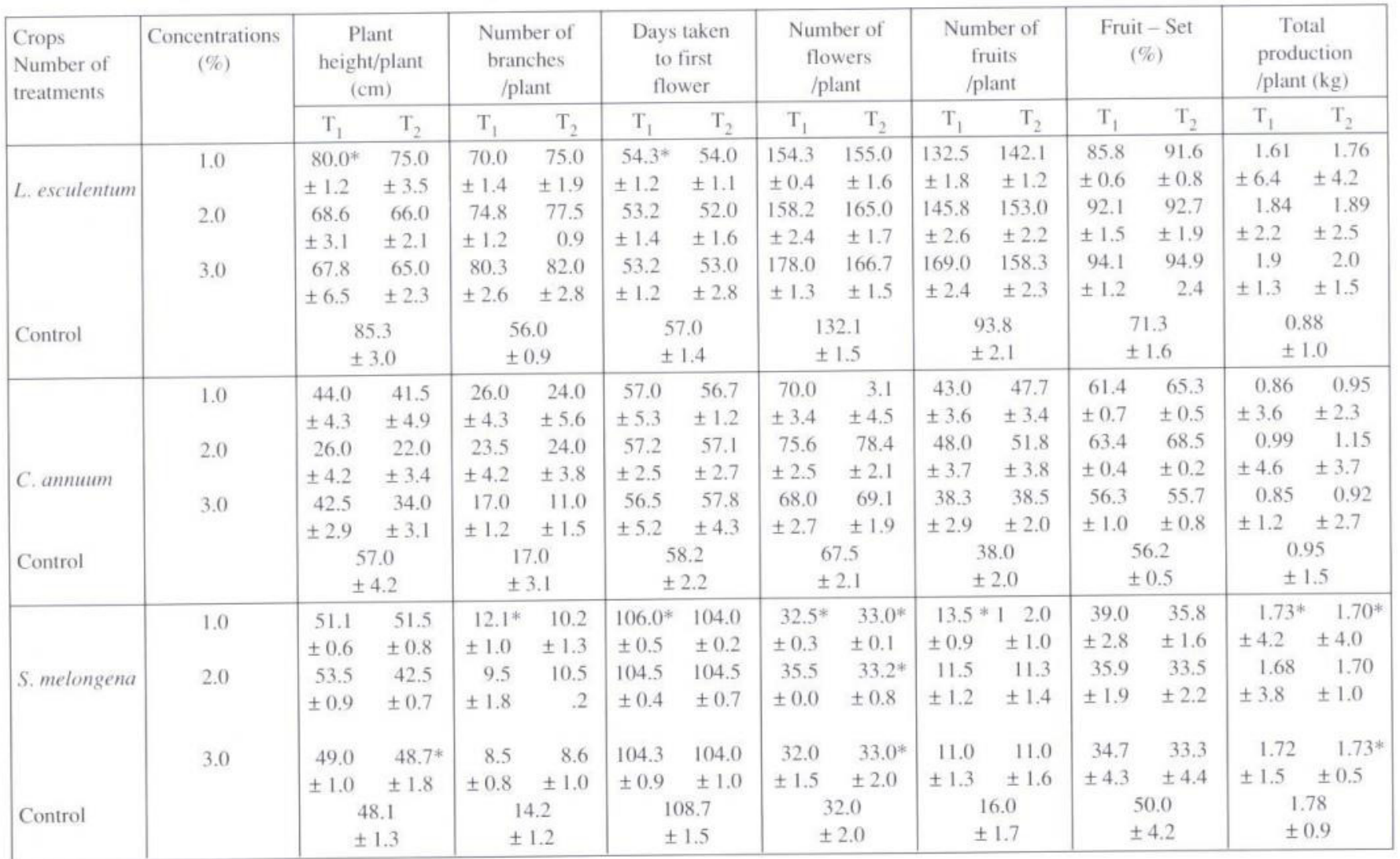

* Non-significant 
to the increase in the concentration. The maximum fruit-set $(94.9 \%)$ was recorded in tomato plants treated twice with $3.0 \%$ of nerivol as compared to $71.3 \%$ in control. On the other hand, the maximum fruit-set $(51.8 \%)$ was recorded in chilli plants treated twice with $2.0 \%$ and in brinjal $12.5 \%$ fruit-set was recorded in plants treated once with $1.0 \%$ as compared $56.2 \%$ and $50.0 \%$ fruit-set in their control plants respectively.

\section{Total yield/plant}

All the treatments with different concentrations of Nevirol caused significant increase in total yield/plant in both tomato and chilli (Table 1). Maximum increase $(2.0 \mathrm{Kg})$ in tomato was recorded in plants treated twice with $3.0 \%$ nevirol as compared to $0.88 \mathrm{Kg}$ total yield/control tomato plant. However, the maximum increase in yield $(1.15 \mathrm{Kg} /$ plant) in chilli plants was obtained by two treatments with $2.0 \%$ nevirol as compared to $0.95 \mathrm{Kg}$ yield/control plant. On the other hand, in brinjal plant the total yield/plant was insignificantly enhanced over their control plants.

\section{Discussion}

From the forgoing observations it is clear that the application of Nevirol enhanced fruit production in tomato (Lycopersicon esculentum), chilli (Capsicum annuum) and brinjal (Solanum melongena). Higher concentration of nevirol $(3.0 \%)$ is useful for tomato. However, for chilli, $2.0 \%$ of nevirol is more effective for increasing fruit-set or fruit production.

Increase in yield in tomato and chilli by the Nevirol. treatments is basically brought about by increase in the number of flowers and fruit-set percentage. Increase in yield in Benincana hispida have been brought about by combined treatments of maleic hydrozide (MH) and morphactin (Singh and Chauhan, 1991). Similarly, number of fruits, fruit weight and femaleness was enhanced in ash gourd (Benincasa hispida) by the treatments with 125 ppm ethrel in combination with $56 \mathrm{ppm}$ morphactin (Chauhan and Singh, 1992). The combined treatments of ethrel and morphactin were more effective then ethrel alone even in higher concentrations. Chauhan et al. (1987) have also reported that castor (Ricinus communis) plant treated with different concentrations of daminozide (B9) exhibit an increase in the number of male and female flowers, number of fruits and seeds per plants. Daminozide, commercially known as Alar or SADH (Succinic acid-2, 2-dimethyl hydrozide), was introduced as a plant growth regulator (Riddle et al., 1962). This is well known for increasing the number of flowers and fruits/plant.

\section{References}

Anonymous, (2000): Nevirol $60 \mathrm{WP}$ - fruit setter preparation. Info sheet A-002. Neviki Research Institute . Budapest, Hungary.

Chauhan, S.V.S.; Saxena, B.K. \& Kinoshita, T. (1987): Effect of Daminozide (B9) on sex-expression and seed setting in castor bean. Ricinus communis. Japan. J. Breed. 37: 262-266.

Chauhan, S.V.S. \& Singh, R.R. (1992): Effects of single and combined treatments of ethrel and morphactin on sex-expression in ash gourd. J. Mendel. 9 (1): 47-49.

Racskó J., Holb I., Szabó Z., Thurzó S., Drén G. \& Nyéki J. (2005): Effect of auxin-synergistic preparation (Nevirol 60 WP) on flowering date and yield of sour-cherry and European plum fruits in Hungary. 10th International Symposium on Plant Bioregulators in Fruit Production. Mexico, Saltillo, 26-30 June 2005, Agenda and Abstracts, 62 .

Rudich, J., A.; Hageman, H.A. \& Anthony, J. (1962): Retardation of plant growth by a new group of chemicals. Science. 136: 191.

Singh, R.R. \& Chauhan, S.V.S. (1991): Effect of maleic hydrazide and morphaztin on sex-expression in Benincasa hispida. J. Mendel. 8 (3\&4): 155-157.

Thurzó S., Racskó J., Veres Zs., Soltész M., Szabó Z., Nyéki J., Drén G., Szabó T. \& Holb I. (2005): Effect of N-phenilphtalamic acid and fertilization on flowering, fruit setting and fruit quality parameters of sweet cherry. 5th International Cherry Symposium. Turkey, Bursa, 6-10 June 2005, Abstracts, 145. 